\title{
Adolescent and adult first time mothers' health seeking practices during pregnancy and early motherhood in Wakiso district, central Uganda
}

\author{
Lynn Atuyambe*1,2,4, Florence Mirembe 2 , Nazarius M Tumwesigye 3 , \\ Johansson Annika ${ }^{4}$, Edward K Kirumira ${ }^{5}$ and Elisabeth Faxelid ${ }^{4}$
}

\begin{abstract}
Address: ${ }^{1}$ Makerere University School of Public Health, Department of Community Health and Behavioural Sciences, P.O. Box 7072, Kampala, Uganda, ${ }^{2}$ Makerere University School of Medicine, Department of Obstetrics and Gynecology, Kampala, Uganda, ${ }^{3}$ Makerere University School of Public Health, Department of Biostatistics and Epidemiology, Kampala, Uganda, ${ }^{4}$ Karolinska Institutet, Department of Public Health Sciences, Division of International Health, IHCAR, SE-17177 Stockholm, Sweden and ${ }^{5}$ Makerere University, Faculty of Social Sciences, Kampala, Uganda

Email: Lynn Atuyambe* - latuyambe@yahoo.com; Florence Mirembe - flomir2002@yahoo.com; Nazarius M Tumwesigye - naz@musph.ac.ug; Johansson Annika - annika.johansson@ki.se; Edward K Kirumira - ekirumira@ss.mak.ac.ug; Elisabeth Faxelid - elisabeth.faxelid@ki.se

* Corresponding author
\end{abstract}

Published: 30 December 2008

Reproductive Health 2008, 5:13 doi:10.1186/1742-4755-5-13
Received: 9 September 2008

Accepted: 30 December 2008

This article is available from: http://www.reproductive-health-journal.com/content/5/I/13

(c) 2008 Atuyambe et al; licensee BioMed Central Ltd.

This is an Open Access article distributed under the terms of the Creative Commons Attribution License (http://creativecommons.org/licenses/by/2.0), which permits unrestricted use, distribution, and reproduction in any medium, provided the original work is properly cited.

\begin{abstract}
Background: Maternal health services have a potentially critical role in the improvement of reproductive health. In order to get a better understanding of adolescent mothers'needs we compared health seeking practices of first time adolescent and adult mothers during pregnancy and early motherhood in Wakiso district, Uganda.

Methods: This was a cross-sectional study conducted between May and August, 2007 in Wakiso district. A total of 762 women (442 adolescents and 320 adult) were interviewed using a structured questionnaire. We calculated odds ratios with their $95 \% \mathrm{Cl}$ for antenatal and postnatal health care seeking, stigmatisation and violence experienced from parents comparing adolescents to adult first time mothers. STATA V. 8 was used for data analysis.

Results: Adolescent mothers were significantly more disadvantaged in terms of health care seeking for reproductive health services and faced more challenges during pregnancy and early motherhood compared to adult mothers. Adolescent mothers were more likely to have dropped out of school due to pregnancy $(\mathrm{OR}=$ $3.6 \mathrm{I}, 95 \% \mathrm{Cl}: 2.40-5.44)$, less likely to earn a salary ( $\mathrm{OR}=0.43,95 \% \mathrm{Cl}: 0.24-0.76)$, and more likely to attend antenatal care visits less than four times compared to adult mothers $(\mathrm{OR}=1.52,95 \% \mathrm{Cl}$ : I. 12-2.07). Adolescents were also more likely to experience violence from parents $(\mathrm{OR}=2.07,95 \% \mathrm{Cl}$ : I.39-3.08) and to be stigmatized by the community $(\mathrm{Cl}=1.58,95 \% \mathrm{Cl}: 1.09-2.59)$. In early motherhood, adolescent mothers were less likely to seek for second and third vaccine doses for their infants [Polio2 (OR $=0.73,95 \% \mathrm{Cl}: 0.55-0.98)$, Polio3 (OR = 0.70: 95\% Cl: 0.5 I-0.95), DPT2 (OR = 0.7I, 95\% Cl: 0.53-0.96), DPT3 (OR = 0.68, 95\% Cl: 0.50-0.92)] compared to adult mothers. These results are compelling and call for urgent adolescent focused interventions.

Conclusion: Adolescents showed poorer health care seeking behaviour for themselves and their children, and experienced increased community stigmatization and violence, suggesting bigger challenges to the adolescent mothers in terms of social support. Adolescent friendly interventions such as pregnancy groups targeting to empower pregnant adolescents providing information on pregnancy, delivery and early childhood care need to be introduced and implemented.
\end{abstract}




\section{Background}

Maternal health services have a potentially critical role in the improvement of reproductive health. The use of health services is related to availability, quality and cost of services as well as the social structures, health beliefs and personal characteristics of the users. According to the World Health Organisation (WHO), over half a million women die each year from complications of pregnancy or childbirth $[1,2]$. Most maternal deaths occur during childbirth and the presence of trained medical staff could greatly reduce this number [3].

During the International Conference on Population and Development (ICPD) held in Cairo in 1994, governments from around the world endorsed the need to promote and protect the rights of adolescents to reproductive health information and care [4]. However, the situation in many countries may not reflect this recognition. In some low income countries where fertility rates are high, teenage pregnancy and early marriage are common. For instance, the proportion of teenage women who are mothers or currently pregnant is highest in sub-Saharan Africa (20-40\%) [5]. As a result, pregnancy and childbirth are the leading cause of death among women adolescents [6,7]. Compared to adult mothers, adolescent mothers are at increased risk of poor maternal and infant outcomes such as maternal and infant death or having an infant who is of low-birth-weight [8-10]. In sub-Saharan Africa, even when services are available, many pregnant women come late for ANC and many attend only once thereby limiting the quality of care provided [11-13]. This hampers the delivery of effective antenatal care (ANC) screening and treatment programs, potentially contributing to the high maternal morbidity and mortality [14]. Young people in particular are reluctant to seek health service for their sexual and reproductive health needs. Included among the many barriers are restrictive laws and policies [15], judgemental health workers and a lack of training in and understanding of adolescent reproductive needs [16]. There is fear among adolescents of humiliation or having to respond to unpleasant questions and procedures. Furthermore, there is lack of respect, privacy and confidentiality within the health care system [4].

The health of women is a human right issue and is a fundamental pillar for progress in low income countries. Addressing reproductive health issues is an important element in the Uganda's National Health Sector Strategic Plan (HSSP II). This plan stipulates that the utilization of maternal and child health services is still inadequate mainly because of low education and cultural practices, including power dynamics at household and community levels [17]. The Uganda demographic and health survey 2006 also established that although some improvements had been made in the area of reproductive health in the previous five years (MMR from 505 down to 435/100,000 live birth; teenage pregnancy from 31 to $25 \%$; use of family planning from 18.6 to $24.4 \%$; four and more ANC visits from 42 to $47 \%$; assistance by skilled providers during birth from 39 to $42 \%$ ) [18], more effort is needed in order to meet the HSSP targets and the Government poverty eradication action plan (PEAP) objectives. Adolescent pregnancy is singled out because of its association with higher morbidity and mortality for both the mother and the child. Besides, schools often terminate adolescents' education and this indirectly affects the health of the mother and the child through loss of socio-economic opportunities.

Understanding adolescents' health seeking behaviour is critical for quality service improvement. We therefore compared the health seeking practices of first time adolescents and adult mothers during pregnancy and early motherhood in Wakiso district, Uganda. This will enable us contribute towards improving reproductive health service delivery and programming for both adolescent and adult mothers in the district.

\section{Methods \\ Study design and setting}

This was a cross-sectional study conducted between May and August 2007 in Wakiso district, which has a total area of $2,704 \mathrm{Km}^{2}$. The district lies in the central region of Uganda and has a population close to one million. It has two counties and one municipality, 17 sub-counties and 130 parishes with an average of four persons per household. In terms of health infrastructure the district has a total of 93 health facilities including two hospitals.

\section{Study population}

The study population included first time mothers (adolescents aged 13-19 and adults 20-29 years) with a child less than one year. This was to ensure that pregnancy, delivery and early motherhood experiences and practices for both groups were comparable.

\section{Sample size and sampling procedures}

Bennett's formula was used to calculate the sample size. The formula also calculates the number of clusters needed to obtain the required sample size [19]. Using Bennett's formula for cluster sampling the overall total sample size was 616 to be drawn from 88 clusters (villages) with each cluster contributing 7 respondents. However, 146 respondents were added to take care of non response. Using the 2000/01 Uganda population and housing census, we obtained a ratio of adolescents to mothers as $6: 4$ and we used it to get the number of adolescent and adult mothers we needed in the study. In total, 762 mothers (442 adolescents and 320 adults) were interviewed. 
A list of villages and their population sizes was obtained from Uganda Bureau of Statistics (UBOS). The selected villages were visited to draw a sampling frame. During this visit, contact with the village leaders and identifying guides for the survey was made. Before data collection, letters were sent to chairpersons of the local councils with details of date of visit and a request for cooperation. Local area council chairpersons were the main point of entry in the field. A mix of multi-stage and cluster sampling techniques was applied (Figure 1).

Using multi-stage sampling method [19] 50 percent of sub-counties were randomly selected from the two counties and municipality. Thereafter, 50 percent of the parishes were randomly selected from each of the selected sub-counties. A number of villages which were proportionate to size of the parish were selected using simple random sampling from each parish. The size of the parish was determined by the number of villages. The more the number of villages in a parish, the more villages selected. The total number of villages selected was 88 . In each cluster (village) we targeted to get at least 9 respondents. In each selected village we constructed two sampling frames, one comprising female adolescents 13-19 and the other adult women 20-29. Those who qualified to be on the sampling frames were first time mothers with a child not more than one year of age. About nine mothers representing nine eligible households (5 adolescent and 4 adult mothers) were randomly selected from each of the 88 villages using simple random sampling technique by using a table of random numbers. In case there was more than one eligible woman in a household, the one with the lowest last digit of their birth day (day of the month) was selected. One follow-up appointment was made in case an interview could not be carried out.

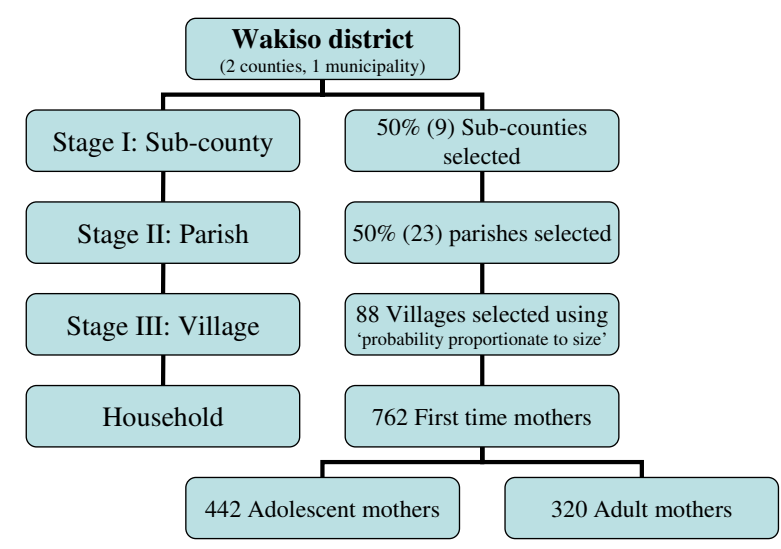

Figure I

This chart illustrates the sampling strategy.

\section{Methods and procedure of data collection}

We used a structured questionnaire with closed and a few open ended questions. Ten female graduate social scientists with experience in field data collection conducted the interviews. They all spoke the local language (Luganda) and received training for five days beforehand. The content of the training included the description of the study objectives, methods of data collection and sampling techniques. The focus of the questionnaire was on health seeking behaviour for curative and preventive services during pregnancy and early motherhood. The questionnaire had five sections, namely: general information, socio-demographic characteristics, general health status, reproductive health and child health. The training comprised a one-toone question and answer simulation exercise including possible responses in the local language. The questionnaire was translated into the local language (Luganda) and back translated into English to ensure consistency of meaning. It was pretested on the fourth day of training in Kasangati (Nangabo sub-county) $15 \mathrm{~km}$ from Kampala city. After a debrief session the questions were refined. All 30 pretested questionnaires were entered in a data entry software [20] and analyzed. These questionnaires are not included in our results. Field procedures, recording and editing answers were reviewed. Written consent was obtained from respondents before interviews begun. Interviews, which lasted for an average of 45 minutes, took place in the compound often under tree shed and sometimes inside the house. Only the respondent was present during the interview.

\section{Quality control}

Field supervisors checked for completeness, consistency and validity of every filled questionnaire before data entry. The first author (LA) conducted debrief meetings every evening to discuss daily field progress and make adjustments where necessary. Extensive validity, consistency and range checks were embedded in the data entry software by the third author (NMT).

\section{Data management and analysis}

The filled questionnaires were entered in the computer using EPIDATA software [20]. These data were then exported to STATA V.8 for data analysis [21]. Frequency distribution of all variables was run to check for any unfamiliar pattern in the process of data entry. Odds ratios (OR) with their corresponding 95\% confidence interval (CI) were calculated. All data analysis was performed using STATA V.8 [21]. Statistical significance was based on $p$ value $<0.05$.

\section{Ethical issues}

Ethical approval was obtained from the higher degrees, research and ethical committees of the Faculty of Medicine Makerere University in Uganda and the regional 
research and ethics committee in Stockholm, Sweden. In addition, permission to conduct the study was obtained from Wakiso district local government. Written informed consent from adult mothers and emancipated minors [22] according to Ugandan ethical guidelines was sought from respondents before interviews began. Participants were informed that there were minimal or no risk to their participation in the study, that participation was voluntary, confidential and that they could withdraw their participation anytime during the interview. They were also informed that refusing to participate would not affect the usual services they normally access at health units.

\section{Results}

\section{Characteristics of respondents}

The mean (SD) age of adolescent mothers was 18 (1.1) years and adult mothers 22 (2.2) years. The majority of mothers (58\% adolescent and $73 \%$ adult) were married or in partnership but adolescent mothers were two times more likely to be single than the adults. Thirty six percent of adult mothers belonged to the Anglican faith while a higher proportion of adolescents were Catholics and Muslims. Half of adolescents and 67 percent of adults had been to secondary school while there were significantly more adolescent mothers with no or incomplete primary education. Adolescent mothers were nearly four times more likely to have dropped out of school due to pregnancy (OR $=3.6,95 \%$ CI: 2.40-5.44) compared to adult mothers. About half of the women in both groups, their spouses/partners provided the main source of income. About 20 percent of the adolescents and 30 percent of the adult mothers mentioned that own salary, trading and farming were the main sources of income. The former group depended more on relatives for income (Table 1).

\section{Pregnancy practices}

Although the majority of adolescent and adult mothers attended ANC at least once, very few (less that 15\%) attended at least once within the first three months of pregnancy. The mean number of times adolescent and adult mothers attended ANC were nearly the same (4.1 and 4.3 respectively), and adolescent mothers were 1.5 times more likely to attend less than four ANC visits (OR $=1.52,95 \%$ CI: 1.12-2.07) compared to adult mothers. There was no difference between adolescents and adults with regard to how early they attended or where they

Table I: Background and socio-demographic characteristic

\begin{tabular}{|c|c|c|c|c|c|c|}
\hline \multirow[b]{2}{*}{ Characteristics } & \multicolumn{2}{|c|}{ Adolescent mothers } & \multicolumn{2}{|c|}{ Adult mothers $*$} & \multirow[b]{2}{*}{ OR } & \multirow[b]{2}{*}{$95 \% \mathrm{Cl}$} \\
\hline & $n=442$ & $\%$ & $n=320$ & $\%$ & & \\
\hline \multicolumn{7}{|l|}{ Marital status } \\
\hline Single & 161 & $(36.4)$ & 73 & $(22.8)$ & 2.01 & $1.44-2.79 *$ \\
\hline Divorced/separated & 26 & $(5.9)$ & 15 & $(4.7)$ & 1.57 & $0.82-3.05$ \\
\hline Married/in partnership (base outcome) & 255 & $(57.7)$ & 232 & $(72.5)$ & & \\
\hline \multicolumn{7}{|l|}{ Education attainment } \\
\hline None/Primary incomplete & 147 & $(33.3)$ & 56 & $(\mid 7.5)$ & 1.98 & $1.36-2.89 *$ \\
\hline Primary complete & 76 & $(17.2)$ & 50 & $(15.6)$ & 1.15 & $0.76-1.74$ \\
\hline Upper/post secondary school & 27 & $(6.1)$ & 69 & $(21.6)$ & 0.30 & $0.18-0.48 *$ \\
\hline Secondary lower (base outcome) & 192 & $(43.4)$ & 145 & $(45.3)$ & & \\
\hline \multicolumn{7}{|l|}{ Religion } \\
\hline Anglican & 103 & $(23.3)$ & 116 & $(36.3)$ & 0.52 & $0.36-0.74 *$ \\
\hline Muslim & 118 & $(26.7)$ & 52 & $(16.3)$ & 1.32 & $0.88-1.99$ \\
\hline Other & 49 & $(11.1)$ & 52 & $(16.3)$ & 0.55 & $0.35-0.87^{*}$ \\
\hline Catholic (base outcome) & 172 & $(38.9)$ & 100 & $(31.3)$ & & \\
\hline \multicolumn{7}{|l|}{ Dropped out school due to pregnancy** } \\
\hline No (base outcome) & 264 & $(63.9)$ & 224 & $(86.5)$ & & \\
\hline Yes & 149 & $(36.1)$ & 35 & $(13.5)$ & 3.61 & $2.40-5.44 *$ \\
\hline \multicolumn{7}{|l|}{ Main source of income } \\
\hline Salary & 20 & $(4.5)$ & 35 & $(10.9)$ & 0.43 & $0.24-0.76^{*}$ \\
\hline Trading & 48 & $(10.7)$ & 48 & $(15.0)$ & 0.75 & $0.48-1.12$ \\
\hline Farming & 24 & $(5.4)$ & 18 & $(5.6)$ & 1.00 & $0.55-1.90$ \\
\hline Relatives & 53 & $(12.0)$ & 17 & (5.3) & 3.33 & $1.30-4.16^{*}$ \\
\hline Mother of adolescent/adult mother & 21 & $(4.8)$ & 6 & (1.9) & 2.62 & $1.03-6.62 *$ \\
\hline Others & 38 & $(8.6)$ & 18 & $(5.3)$ & 1.58 & $0.87-2.86$ \\
\hline Spouse/partner (base outcome) & 238 & $(53.9)$ & 178 & $(54.5)$ & & \\
\hline Mean age (sd) & $17.9(1.1)$ & & $22.3(2.2)$ & & & \\
\hline Mean age of first sex (sd) & $15.9(4.3)$ & & $18.4(8.1)$ & & & \\
\hline Mean (sd.) age of first marriage & $16.8(1.3)$ & & $20.1(2.6)$ & & & \\
\hline
\end{tabular}

¥Reference group; *statistically significant; N.B. Odds among adolescent mothers are divided by odds among adult mothers

**For only those who had been to school 
sought ANC services. Both groups mainly attended public health institutions (Table 2).

\section{Problems experienced during pregnancy}

The women were asked about social, economic and health problems experienced during pregnancy. Almost half of both adolescents and adults said that they had experienced frequent ailments during pregnancy, such as malaria fever, swollen legs, anaemia and morning sickness. Seventeen percent of adolescent mothers said that they had lacked sufficient food during pregnancy, compared to 13 percent among the adult mothers. Significant differences between the adolescents and adults were found in terms of likelihood of being rejected by partners, victim of violence by parents and being sent away from school and/or home. Adolescent mothers were more likely to be inappropriately dressed [Self and community perception - dress no longer fitting because of pregnancy] (OR $=1.79,95 \% \mathrm{CI}: 1.29-2.49)$ during pregnancy and to be stigmatised by the community $(\mathrm{OR}=1.58,95 \% \mathrm{CI}$ : 1.09-2.59) compared to adult mothers. Adolescent mothers were more likely to lack disposable income compared to adult mothers $(\mathrm{OR}=1.64,95 \% \mathrm{CI}: 1.20-2.24)$. Up to 40 percent of mothers feared that they might die while giving birth while more than one third was not certain that their infants would survive birth. These uncertainties were significantly more common among the adolescent mothers compared to the adult mothers (Table 3).

\section{Delivery practices}

Over 85 percent of women were assisted by health practitioners at health units during delivery. There was no statistically significant difference between adolescents and adults with regard to where they gave birth and who assisted them. Adolescent mothers were nearly two and a half times more likely to be advised by relatives where to give birth $(\mathrm{OR}=2.45,95 \% \mathrm{CI}: 1.21-4.91)$ compared to adult mothers. Around 40 percent of all mothers either walked or travelled by motorcycle when labour began. About half of the mothers indicated that lack of money was a major barrier to seeking biomedical health care (Table 4).

\section{Breast feeding and supplementary feeding}

Over 95 percent of women had ever breast-fed but several kinds of feeds such as sugar/glucose water, ghee in mushroom soup were given before breast milk started to flow. Adolescent mothers were more likely to delay initiation of breast feeding (OR = 1.48, 95\% CI: 1.00-2.17) compared to adult mothers. They started breastfeeding after two days till breast milk flow. Most mothers (65\%) introduced solid foods at six months or later (Table 5).

\section{Childhood immunization}

In general, vaccination coverage (using vaccination card method) was high (69\%). Adolescent mothers were significantly less likely to report possession of a vaccination card compared to adult mothers. Adolescent mothers were also less likely to seek for subsequent doses compared to adult mothers [Polio2 (OR $=0.73,95 \% \mathrm{CI}: 0.55-$ 0.98), Polio3 (OR=0.70: 95\% CI: 0.51-0.95), DPT2 (OR $=0.71,95 \%$ CI: 0.53-0.96), DPT3 $(\mathrm{OR}=0.68,95 \% \mathrm{CI}$ : $0.50-0.92)]$. However, we did not observe any difference between adolescents and adults regarding measles and Vitamin A supplementation (Table 6).

\section{Discussion}

This study demonstrates that adolescent mothers were significantly more disadvantaged in terms of health care seeking for maternal and child health services and faced

Table 2: Adolescent and adult mothers pregnancy related practices

\begin{tabular}{|c|c|c|c|c|c|c|}
\hline \multirow[b]{2}{*}{ Health seeking practices } & \multicolumn{2}{|c|}{ Adolescent mothers } & \multicolumn{2}{|c|}{ Adult mothers $¥$} & \multirow[b]{2}{*}{ OR } & \multirow[b]{2}{*}{$95 \% \mathrm{Cl}$} \\
\hline & $n=442$ & $(\%)$ & $n=320$ & $(\%)$ & & \\
\hline \multicolumn{7}{|l|}{ ANC during pregnancy $(n=761)$} \\
\hline No (base outcome) & 12 & $(2.7)$ & 5 & $(1.6)$ & & \\
\hline Yes & 429 & $(97.3)$ & 315 & $(98.4)$ & 0.57 & $0.20-1.63$ \\
\hline \multicolumn{7}{|c|}{ Months of pregnancy at first ANC visit? $(n=744)$} \\
\hline One to three months & 54 & $(12.6)$ & 47 & $(14.9)$ & 0.82 & $0.54-1.25$ \\
\hline Four and above months (Base outcome) & 375 & $(87.4)$ & 268 & $(85.1)$ & & \\
\hline \multicolumn{7}{|l|}{ Number of ANC visits? $(n=742)$} \\
\hline Less than four times & 171 & $(40.0)$ & 96 & $(30.5)$ & 1.52 & $1.12-2.07^{*}$ \\
\hline Four and above (base outcome) & 256 & $(60.0)$ & 219 & $(69.5)$ & & \\
\hline Mean Number of ANC visits & 4.1 & & 4.3 & & & \\
\hline \multicolumn{7}{|l|}{ Place for ANC $(n=729)$} \\
\hline Public hospital & $|4|$ & $(33.8)$ & 107 & (34.3) & 0.87 & $0.62-1.21$ \\
\hline Private hospital/clinic & 77 & $(18.5)$ & 74 & $(23.7)$ & 0.68 & $0.46-1.01$ \\
\hline Public health centre [base outcome] & 199 & $(47.7)$ & $|3|$ & $(42.0)$ & & \\
\hline
\end{tabular}

${ }^{\sharp}$ reference group; *statistically significant; N.B. Odds among adolescent mothers are divided by odds among adult mothers 
Table 3: Experienced problems during pregnancy

\begin{tabular}{|c|c|c|c|c|c|c|}
\hline \multirow[b]{2}{*}{ Experiences problems } & \multicolumn{2}{|c|}{ Adolescent mothers } & \multicolumn{2}{|c|}{ Adult mothers ${ }^{*}$} & \multirow[b]{2}{*}{ OR } & \multirow[b]{2}{*}{$95 \% \mathrm{Cl}$} \\
\hline & $n=442$ & $\%$ & $n=320$ & $\%$ & & \\
\hline \multicolumn{7}{|c|}{ Frequent ailments $(n=756)$} \\
\hline No (base outcome) & 235 & $(53.4)$ & 168 & $(53.2)$ & & \\
\hline Yes & 205 & $(46.6)$ & 148 & $(46.8)$ & 0.99 & $0.74-1.32$ \\
\hline \multicolumn{7}{|c|}{ Lack of enough food $(n=754)$} \\
\hline No (base outcome) & 362 & $(82.6)$ & 275 & $(87.0)$ & & \\
\hline Yes & 76 & $(17.4$ & 41 & $(13.0)$ & 1.41 & $0.93-2.12$ \\
\hline \multicolumn{7}{|c|}{ Violence from partner $(n=755)$} \\
\hline No (base outcome) & 399 & (9l.3) & 284 & (89.3) & & \\
\hline Yes & 38 & $(8.7)$ & 34 & $(10.7)$ & 0.79 & $0.49-1.29$ \\
\hline \multicolumn{7}{|c|}{ Rejection by partner $(n=725)$} \\
\hline No (base outcome) & 358 & $(84.6)$ & 272 & $(90.1)$ & & \\
\hline Yes & 65 & $(15.4)$ & 30 & $(9.9)$ & 1.65 & $1.04-2.6 I^{*}$ \\
\hline \multicolumn{7}{|c|}{ Violence from parents $(n=726)$} \\
\hline No (base outcome) & 319 & $(75.6)$ & 263 & $(86.5)$ & & \\
\hline Yes & 103 & $(24.4)$ & 41 & $(13.5)$ & 2.07 & I.39-3.08* \\
\hline \multicolumn{7}{|c|}{ Sent away from home $(n=708)$} \\
\hline No (base outcome) & 369 & $(89.4)$ & 289 & $(90.0)$ & & \\
\hline Yes & 44 & $(10.7)$ & 6 & $(2.0)$ & 5.94 & $2.50-14.11 *$ \\
\hline \multicolumn{7}{|c|}{ Expelled from school $(n=723)$} \\
\hline No (base outcome) & 375 & (89.3) & 297 & $(98.0)$ & & \\
\hline Yes & 45 & $(10.7)$ & 6 & $(2.0)$ & 5.94 & $2.50-14.11 *$ \\
\hline \multicolumn{7}{|c|}{ Stigmatized by community $(n=725)$} \\
\hline No (base outcome) & 346 & $(82.0)$ & 268 & (88.4) & & \\
\hline Yes & 76 & $(18.0)$ & 35 & $(11.6)$ & 1.58 & $1.09-2.59 *$ \\
\hline \multicolumn{7}{|c|}{ Inappropriate dressing $(n=753)$} \\
\hline No (base outcome) & 288 & $(65.8)$ & 244 & (77.5) & & \\
\hline Yes & 150 & $(34.3)$ & 71 & $(22.5)$ & 1.79 & $1.29-2.49 *$ \\
\hline \multicolumn{7}{|c|}{ Lack of disposable income $(n=252)$} \\
\hline No (base outcome) & 267 & $(61.1)$ & 227 & $(72.1)$ & & \\
\hline Yes & 170 & $(38.9)$ & 88 & $(27.9)$ & 1.64 & $1.20-2.24 *$ \\
\hline \multicolumn{7}{|c|}{ Uncertainty of child survival $(n=755)$} \\
\hline No (base outcome) & 270 & $(61.5)$ & 207 & $(65.5)$ & & \\
\hline Yes & 169 & $(38.5)$ & 109 & (34.5) & 1.19 & $0.88-1.6 \mid$ \\
\hline \multicolumn{7}{|c|}{ Uncertainty of own survive during delivery $(n=755)$} \\
\hline No (base outcome) & 243 & $(55.4)$ & 201 & $(63.6)$ & & \\
\hline Yes & 196 & $(44.6)$ & 115 & $(36.4)$ & 1.41 & $1.04-1.90 *$ \\
\hline \multicolumn{7}{|c|}{ Uncertainty of continuing education after delivery $(n=737)$} \\
\hline No (base outcome) & 362 & $(84.2)$ & 283 & $(92.2)$ & & \\
\hline Yes & 68 & $(15.8)$ & 24 & $(7.8)$ & 2.22 & $1.36-\left.3.6\right|^{*}$ \\
\hline
\end{tabular}

¥Reference group; *statistically significant; N.B. Odds among adolescent mothers are divided by odds among adult mothers

more challenges during pregnancy and early motherhood compared to adult mothers. Adolescent mothers were more likely to drop out of school due to pregnancy, less likely to earn a salary, and more likely to attend ANC fewer times compared to adult mothers. Adolescents were also more likely to experience violence from parents, to be rejected by the partner, and to be stigmatized. In early motherhood, adolescent mothers were less likely to seek for second and third vaccine doses for their infants compared to adult mothers. These results are compelling and call for urgent adolescent focused interventions.

The adolescents were less educated. They were twice more likely to have no or incomplete primary education and significantly less likely to have attended primary upper or post secondary education compared to the adult mothers. Financial constrains and low education levels have implications for the uptake of health services and how to correctly understand and implement health education messages. Adolescent pregnancy greatly affects education and we note that over one third of adolescent mothers dropped out of school due to pregnancy. Moreover, adolescents were more likely to have dropped out of school due to pregnancy compared to adult mothers. The difference could have been due to the age difference. Another possible explanation could be that currently sexual initiation starts quite early as indicated in the results. Besides, adolescents got married or involved in partnership earlier 
Table 4: Adolescent mothers and adult mothers delivery practices

\begin{tabular}{|c|c|c|c|c|c|c|}
\hline \multirow[b]{2}{*}{ Characteristics } & \multicolumn{2}{|c|}{ Adolescent mothers } & \multicolumn{2}{|c|}{ Adult mothers $¥$} & \multirow[b]{2}{*}{ OR } & \multirow[b]{2}{*}{$95 \% \mathrm{Cl}$} \\
\hline & $n=442$ & $\%$ & $\mathbf{n}=\mathbf{3 2 0}$ & $\%$ & & \\
\hline \multicolumn{7}{|l|}{ Assistance during delivery $(n=76 I)$} \\
\hline Doctor & 57 & $(12.9)$ & 41 & $(12.8)$ & 1.05 & $0.68-1.63$ \\
\hline Nurse aide & 31 & $(7.0)$ & 18 & $(5.6)$ & 1.30 & $0.7 I-2.38$ \\
\hline TBA & 19 & $(4.3)$ & 18 & $(5.6)$ & 0.80 & $0.4 I-1.55$ \\
\hline Relative/friend/Others & 45 & $(10.2)$ & 25 & (7.8) & 1.36 & $0.81-2.28$ \\
\hline Midwife/nurse (base outcome) & 289 & $(65.5)$ & 218 & $(68.1)$ & & \\
\hline \multicolumn{7}{|l|}{ Place of birth $(n=758)$} \\
\hline Own home & 34 & (7.7) & 16 & $(5.0)$ & 1.63 & $0.85-3.10$ \\
\hline TBA's home & 15 & $(3.4)$ & 14 & $(4.4)$ & 0.82 & $0.38-1.77$ \\
\hline Public health centre & 99 & $(22.6)$ & 78 & $(24.5)$ & 0.97 & $0.66-1.43$ \\
\hline Private hospital/clinic & 146 & $(33.3)$ & 100 & $(31.3)$ & 1.12 & $0.78-1.59$ \\
\hline Public hospital (base outcome) & 145 & $(33.0)$ & 111 & $34.8)$ & & \\
\hline \multicolumn{7}{|l|}{ Reasons for choice of delivery place $(n=746)$} \\
\hline Public Hospital with all facilities & 50 & $(11.7)$ & 47 & $(14.6)$ & 0.89 & $0.56-1.43$ \\
\hline Father of child made decision & 9 & $(2.1)^{\prime}$ & 12 & $(3.8)$ & 0.62 & $0.25-1.52$ \\
\hline Complication requiring hospital & 36 & (8.4) & 22 & (7.0) & 1.35 & $0.75-2.42$ \\
\hline Free medical care & 34 & (7.9) & 21 & (6.6) & 1.33 & $0.73-2.42$ \\
\hline Lack of money & 17 & $(4.0)$ & 14 & (4.4) & 1.00 & $0.47-2.11$ \\
\hline Referred & 39 & $(9.1)$ & 21 & (6.7) & 1.53 & $0.85-2.74$ \\
\hline Advised by relative & 47 & $(I I .0)$ & 15 & $(4.7)$ & 2.58 & $1.37-4.85^{*}$ \\
\hline Others & 8 & $(1.8)$ & 16 & $(5.1)$ & 0.41 & $0.17-0.99$ \\
\hline Private hospital & 18 & (4.2) & 13 & (4.4) & 1.14 & $0.54-2.42$ \\
\hline Abrupt labour pain/at night & 29 & $(6.8)$ & 20 & $(6.6)$ & 1.19 & $0.64-2.22$ \\
\hline Near ANC facility (base outcome) & $|4|$ & $(32.9)$ & 116 & $(36.7)$ & & \\
\hline \multicolumn{7}{|l|}{ Mode of mode of transport $(n=730)$} \\
\hline Commercial motorcycle/bicycles (Boda-boda) & 109 & $(25.6)$ & 72 & $(23.6)$ & 0.96 & $0.90-1.01$ \\
\hline Walking & 70 & $(16.4)$ & 53 & $(17.3)$ & 0.96 & $0.90-1.04$ \\
\hline Public transport/taxi & 121 & $(28.4)$ & 77 & $(25.3)$ & 0.95 & $0.90-1.01$ \\
\hline Others & 17 & $(4.0)$ & 6 & $(2.0)$ & 0.87 & $0.76-1.01$ \\
\hline Car/private taxi (base outcome) & 109 & $(25.6)$ & 97 & $(31.8)$ & & \\
\hline \multicolumn{7}{|c|}{ Major barriers to health seeking for biomedical care $(n=53 I)$} \\
\hline Fear to be found HIV positive & 32 & $(10.3)$ & 26 & $(11.9)$ & 1.28 & $0.73-2.25$ \\
\hline Rude health workers & 19 & $(6.1)$ & 14 & $(6.4)$ & 1.16 & $0.56-2.40$ \\
\hline Long distances & 10 & (3.2) & 9 & $(4.1)$ & 1.42 & $0.56-3.59$ \\
\hline Prefer herbal & 7 & $(2.2)$ & 11 & $(5.2)$ & 2.47 & $0.93-6.56$ \\
\hline Others & 43 & $(13.8)$ & 30 & $(13.8)$ & 1.10 & $0.75-1.84$ \\
\hline Lack of money (base outcome) & 202 & $(64.5)$ & 128 & $(58.7)$ & & \\
\hline
\end{tabular}

$¥$ reference group; *significant findings; N.B. Odds among adolescent mothers are divided by odds among adults mother

than adult mothers. There is evidence that no or low education positively correlates with early sexual activity especially among women [18]. This may imply that sexual education is still lacking or has not yet taken root and needs to be started at early age.

The majority of mothers attended ANC at least once. This proportion is comparable to the one observed in the 2006 Uganda demographic and health survey [18]. However, the majority initiate ANC late, i.e. after three months of pregnancy. According to WHO whose guidelines Uganda adopted, a pregnant woman should attend ANC at least once before 16 weeks of gestation $[14,23]$. Although over 60 percent attended ANC four times and above, still many women especially adolescents do not meet the minimum standard of four times. Antenatal care attendance is related to place of childbirth. According the 2006 Demographic and Health Survey, births to women who made four or more antenatal care visits are almost four times more likely to occur in a health facility than births to women who did not attend antenatal care [18]. More recently, the WHO has suggested that goal-oriented antenatal care may achieve similar health outcomes as the more rigorous schedule $[23,24]$. This means that each visit should include care that is appropriate to the overall condition and stage of pregnancy such as: identification of pre-existing health conditions, early detection of complications, health promotion and disease prevention, birth preparedness, and complication planning. Reasons why adolescent mothers attend ANC fewer times might be lack of operational logistics such as money for transport, low education level or the socioeconomic and gender dynam- 
Table 5: Breastfeeding and supplementary feeding among adolescent mothers and adult mothers

\begin{tabular}{|c|c|c|c|c|c|c|}
\hline \multirow[b]{2}{*}{ Variable } & \multicolumn{2}{|c|}{ Adolescent mothers } & \multicolumn{2}{|c|}{ Adult mothers $*$} & \multirow[b]{2}{*}{ OR } & \multirow[b]{2}{*}{$95 \% \mathrm{Cl}$} \\
\hline & $n=442$ & $\%$ & $\mathbf{n}=\mathbf{3 2 0}$ & $\%$ & & \\
\hline \multicolumn{7}{|l|}{ Ever Breastfed $(n=76 I)$} \\
\hline No (Base outcome) & 15 & (3.4) & 19 & $(5.9)$ & & \\
\hline Yes & 426 & $(96.6)$ & 301 & $(94.1)$ & 1.79 & $0.87-3.58$ \\
\hline \multicolumn{7}{|c|}{ Start of breastfeeding after birth $(n=724)$} \\
\hline Immediately (less that I hour) & 143 & $(33.8)$ & 115 & $(38.2)$ & 0.96 & $0.68-1.34$ \\
\hline Days (2 till breast milk started flowing) & 119 & $(28.1)$ & 62 & $(20.6)$ & 1.48 & $1.00-2.17^{*}$ \\
\hline Hours (I to 24) (base outcome) & 161 & $(38.1)$ & 124 & $(41.2)$ & & \\
\hline \multicolumn{7}{|c|}{$\begin{array}{l}\text { Child given some supplements before breast milk started flowing } \\
(n=754)\end{array}$} \\
\hline No & 175 & $(40.1)$ & $(123)$ & 38.8 & & \\
\hline Yes & 262 & $(59.9)$ & (194) & 61.2 & 0.95 & $0.7 I-1.28$ \\
\hline \multicolumn{7}{|c|}{ Supplements given before breast milk started flowing $(n=397)$} \\
\hline Milk other than breast milk & 21 & $(8.8)$ & 20 & $(10.3)$ & 0.69 & $0.35-1.35$ \\
\hline Plain water & 45 & $(17.3)$ & 47 & $(24.3)$ & 0.63 & $0.38-1.03$ \\
\hline Tea infusions & 32 & $(12.3)$ & 28 & $(14.4)$ & 0.75 & $0.42-1.34$ \\
\hline Ghee/mushroom soup & 37 & $(14.2)$ & 17 & $(8.8)$ & 1.43 & $0.75-2.70$ \\
\hline Sugar/glucose water (base outcome) & 125 & $(48.1)$ & 82 & $(42.3)$ & & \\
\hline \multicolumn{7}{|c|}{ Still breastfeeding (at time of survey) $(n=466)$} \\
\hline No (outcome base) & 27 & $(10.0)$ & 33 & $(16.8)$ & & \\
\hline Yes & 243 & $(90.0)$ & 163 & (83.2) & 1.82 & $1.06-3.14^{*}$ \\
\hline \multicolumn{7}{|l|}{ Introduction of solid foods } \\
\hline less than 6 months & 86 & $(35.0)$ & 74 & $(34.1)$ & & \\
\hline 6 months and later (base outcome) & 160 & $(65.0)$ & 143 & $(65.9)$ & 0.96 & $(0.65-1.40)$ \\
\hline
\end{tabular}

$¥$ reference group; *significant findings; N.B. Odds among adolescent mothers are divided by odds among adult mothers

ics in their homes or families as suggested in literature [25-27]. Socially, being inappropriately dressed and stigmatized makes adolescents keep away from the public $[28,29]$. As long as effective strategies such as to increase birth attendance by skilled personnel, provide emergence obstetric care and promote institutional deliveries remain unmet, the rate of maternal morbidity and mortality in low income countries will remain high.

Adolescents experienced several problems during pregnancy. They faced rejection and violence from partners and parents. The likely reason for rejection is that partners

Table 6: Childhood immunization among adolescent mothers and adult mothers

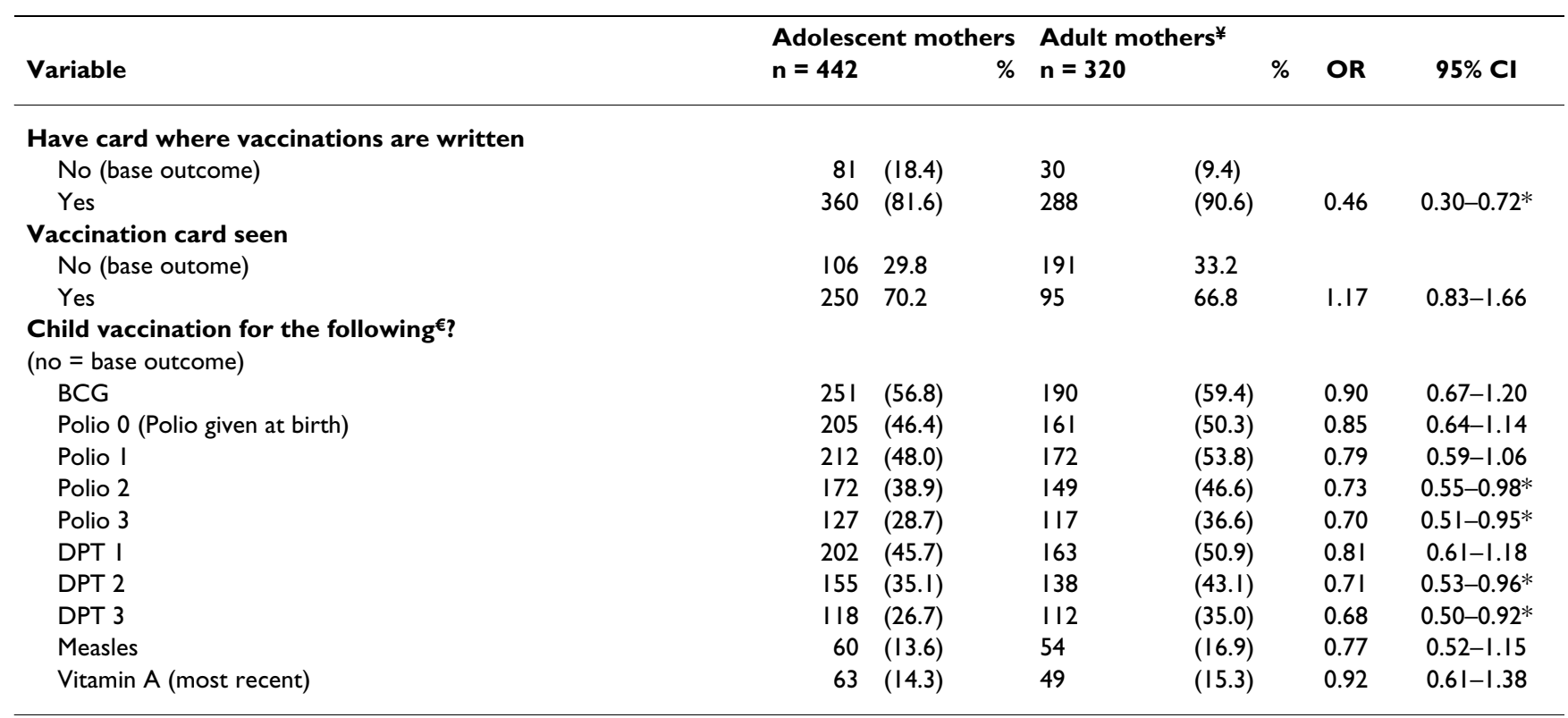

$¥$ reference group; *statistically significant; $€$ data transcribed from vaccination card; N.B. Odds among adolescent mothers are divided by odds among adult mothers 
shun responsibility for parenthood. They feel they do not have the capacity to take on the family responsibility. Previous studies confirm that men/boys deny impregnating women, especially adolescents, because they feel they are not ready to take on the responsibility [30]. Furthermore, women, especially adolescent mothers were sent away from home and expelled from school. This could be because of reactions from parents feeling that their daughter has wasted scarce resources. This is in line with results from a qualitative study conducted earlier in the same setting [28]. In central Uganda, it is widely believed that unmarried pregnant girls should not stay in the same house as their parents, and teenage pregnancy brings shame to the family. It is a well known fact that violence affects women's health. Women experiencing violent situations are often unable to make sexual and reproductive health choices and this exposes them to many health risks as observed in the same setting [31,32]. Sadly most women remain silent about violence by an intimate partner and do not seek help $[33,34]$. This also has socio-psychological implications to the young pregnant mothers.

Our findings suggest that adolescent mothers faced more challenges in terms of stigma from the community because of pregnancy state and lack of disposable income. This also affected the health seeking behaviour for maternal and child health services. Furthermore, over one third of pregnant women were worried of death while giving birth and anxious about whether their child will survive. Adolescent mothers were significantly more worried of dying while giving birth compared to adult mothers. This uncertainty is probably explained by the high maternal mortality ratio and infant mortality rate $(435 / 100,000$ and 76/1,000, respectively) [18] in Uganda. Probably adolescents observe death of women and children frequently in the community. The fear of death could also be compounded by lack of support from close people such as parents and partners. Lack of information and support from the health system including health workers is another possible explanation.

Despite these challenges observed, the majority of mothers were assisted by trained health personnel during labour. Only ten percent gave birth at home or at the TBAs home compared to the 2006 UDHS where 58 percent of mothers are said to deliver at home [18]. The problem of home deliveries becomes illuminated when need for emergency obstetric care arises. Other studies too suggest that choice of place of delivery has consistently been found associated with negative maternal and neonatal outcomes $[35,36]$. Child birth attended by skilled personnel in a health facility is associated with lower rates of maternal and neonatal mortality and morbidity than home births [1,3]. Proximity to health facilities influenced choice of delivery place for both adolescent and adult mothers. A study conducted in rural Uganda suggested that physical access, proximity and attitude of health staff influences health seeking behaviour for maternal services [37].

Like other studies have documented in Uganda, nearly all mothers breastfed their babies though not exclusively $[18,38]$. However, we discovered that adolescent mothers were more likely to delay initiating breastfeeding for several days [Days ranged from 2 till breast milk started flowing] after delivery compared to adult mothers. This could possibly be a result of anxiety, inadequate support, and ignorance about breastfeeding. Besides, before breast milk started to flow, several fluids were given to the babies including tea, mushroom soup with ghee, and glucose. As suggested in the literature this practice could potentially be harmful to the health of the baby [39]. Overall, WHO encourages exclusive breastfeeding for the first six months of life and discourages unnecessary use of breast milk substitutes for those women who do not know their HIV serostatus. We postulate that there is a gap in information to young women after delivery from health providers

Vaccination practices for children are considered a good proxy indicator for health seeking behaviour in early motherhood [40]. Adolescent mothers were significantly less likely to report possession of a vaccination card for childhood diseases. We also observed that children of adolescent mothers were significantly less likely to receive the second and third doses of Poliomyelitis and Diphtheria vaccines. This might be due to lack of money for transport, social support [This refers to the support offered by the social network in terms of advice, information, counseling, financial, material and emotional support], and health education, which is usually given during ANC visits. Similar to our study, recent research done on adolescents' use of maternal and child health services in low income countries including Uganda showed that infants born to adolescents were less likely to receive vaccinations than infants born to adult mother [7].

We note that our inclusion criteria leave out mothers who could have lost their babies in infancy. This is a limitation as we cannot tell where they sought healthcare. This could partly explain the higher proportion of mothers assisted by trained health workers during delivery compared to the national statistics.

\section{Conclusion}

This study demonstrated bigger challenges to the adolescent mothers in terms of social support, stigmatisation and violence. It also showed a high attendance to a skilled provider for maternity services. Regardless of the above, adolescents still showed poorer health seeking behaviour for themselves and their children. Adolescents made fewer 
ANC visits compared to adult mothers. Care of the newborn was poor for the adolescents as evidenced in the delayed initiation of breast feeding and inappropriate feeds given to the newborns before the initiation of breastfeeding. We propose comprehensive adolescent SRH programmes to reduce the severe consequences of early sexual activity. Adolescent friendly interventions such as pregnancy groups targeting empowering pregnant adolescents with information on pregnancy, delivery and early childhood care should be introduced and implemented to improve their health and that of their infants. The intriguing phenomenon of early motherhood calls for enhanced access to reproductive health services especially the never-married women. Sexual education should begin before puberty. This might offer an opportunity to girls to make informed choices about their sexual activities.

\section{Competing interests}

The authors declare that they have no competing interests.

\section{Authors' contributions}

LA, FM, EF, AJ \& EKK contributed to the study concept and design; LA \& NMT were responsible for supervision of fieldwork and the acquisition of data; data analysis and interpretation was performed by LA, NMT, FM, EF, EKK, $\mathrm{AJ}$; the manuscript was drafted by LA; the manuscript was revised critically for substantial intellectual content by LA, NMT, FM, EF, EKK, AJ.

\section{Acknowledgements}

The authors extend thanks to the survey interviewers and field supervisors especially Warren Aryeija who assisted with data collection and to the mothers from Wakiso district who shared their experiences with us. We are also very grateful for the statistical support given by Kasasa Simon from the Swiss Tropical Institute, Basel Switzerland/MUSPH and Richard Muwonge from Tampere School of Public Health, University of Tampere, Helsinki Finland. Thanks to Fred Makumbi (MUSPH) reviewed and provided comments on the manuscript before submission. We are indebted to Raymond Wamalwa who was very helpful in data entry and processing. The authors acknowledge with gratitude funding for this research from Side/ SAREC through Makerere University-Karolinska Institutet PhD Research Collaboration

\section{References}

I. Stephenson R, Baschieri A, Clements S, Hennink M, Madise N: Contextual influences on the use of health facilities for childbirth in Africa. American journal of public health 2006, 96(I):84-93.

2. United Nations Children's Fund: PROGRESS FOR CHILDREN. A report Card on Maternal Mortality. New York: UNICEF; 2008.

3. Howlader AA, Kabir M, Bhuiyan MM: Health-seeking behaviour of mothers and factors affecting infant and child mortality. Demography India 1999, 28(2):225-238.

4. Rice M: Adolescent sexual and reproductive health. Reproductive biomedicine online 2000, I(3):78-86.

5. Westoff CF: Trends in marriage and early child bearing in developing countries. Calverton, MD, USA: ORG Macro; 2003.

6. Mayor S: Pregnancy and childbirth are leading causes of death in teenage girls in developing countries. BMJ (Clinical research ed) 2004, 328(7449): I I 52 .
7. Reynolds HW, Wong EL, Tucker H: Adolescents' use of maternal and child health services in developing countries. International family planning perspectives 2006, 32(1):6-16.

8. LeGrand TK, Mbacke CS: Teenage pregnancy and child health in the urban Sahel. Studies in family planning 1993, 24(3): 137-149.

9. Magadi M, Diamond I, Madise N: Analysis of factors associated with maternal mortality in Kenyan hospitals. Journal of biosocial science 200I, 33(3):375-389.

10. Becher H, Muller O, Jahn A, Gbangou A, Kynast-Wolf G, Kouyate B: Risk factors of infant and child mortality in rural Burkina Faso. Bulletin of the World Health Organization 2004, 82(4):265-273.

II. Peltzer K, Ajegbomogun B: Utilisation of antenatal care in a Nigerian teaching hospital. African journal of reproductive health 2005, 9(3):|159-|6|.

12. Waiswa P, Kemigisa M, Kiguli J, Naikoba S, Pariyo GW, Peterson S: Acceptability of evidence-based neonatal care practices in rural Uganda - implications for programming. BMC pregnancy and childbirth 2008, 8:21.

13. Gharoro EP, lgbafe AA: Antenatal care: some characteristics of the booking visit in a major teaching hospital in the developing world. Med Sci Monit 2000, 6(3):519-522.

14. Myer L, Harrison A: Why do women seek antenatal care late? Perspectives from rural South Africa. Journal of midwifery \& women's health 2003, 48(4):268-272.

15. Tylee A, Haller DM, Graham T, Churchill R, Sanci LA: Youthfriendly primary-care services: how are we doing and what more needs to be done? Lancet 2007, 369(9572): 1565 -1573.

16. World Health Organisation: Adolescent Friendly Health Services: An Agenda for Change. Geneva: WHO; 2002.

17. Ministry of Health [Uganda]: Health Sector Strategic Plan II 2005/06 - 2009/201 0. Kampala: MoH; 2005.

18. Uganda Bureau of Statistics (UBOS) and Macro International Inc: Uganda Demographic and Health Survey 2006. Calverton, Maryland, USA: UBOS and Macro International Inc; 2007.

19. Bennett S, Woods T, Liyanage WM, Smith DL: A simplified general method for cluster-sample surveys of health in developing countries. World Health Stat $Q$ 1991, 44(3):98-106.

20. Lauritsen JM: EpiData Data Entry, Data Management and basic Statistical Analysis System. V3.I edition. 2000 [Http:// www.epidata.dk]. Odense Denmark: EpiData Association Viewed on 0I-0I-2007

21. STATA Corp LP: Data analysis and statistical software. V.8.2 edition. 2008 [http://stata.com/] . viewed on 0I-0I-2007

22. Uganda National Council for Science and Technology (UNCST): National Guidelines for Research involving Human Subjects as research Participants - Uganda. Kampala: UNCST; 2007.

23. Berg CJ: Prenatal care in developing counties: the World Health Organization technical working group on antenatal care. Journal of the American Medical Women's Association (1972) 1995, 50(5): 182-186.

24. Villar J, Ba'aqeel H, Piaggio G, Lumbiganon P, Miguel Belizan J, Farnot U, Al-Mazrou Y, Carroli G, Pinol A, Donner A, et al.: WHO antenatal care randomised trial for the evaluation of a new model of routine antenatal care. Lancet 200I, 357(9268): I55I-I564.

25. Morris DL, Berenson AB, Lawson J, Wiemann CM: Comparison of adolescent pregnancy outcomes by prenatal care source. The Journal of reproductive medicine 1993, 38(5):375-380.

26. Boult BE, Cunningham PW: Some aspects of obstetrics in black teenage pregnancy: a comparative analysis. Medicine and law 1995, I4(I-2):93-97.

27. Brabin L, Verhoeff FH, Kazembe P, Brabin BJ, Chimsuku L, Broadhead $R$ : Improving antenatal care for pregnant adolescents in southern Malawi. Acta obstetricia et gynecologica Scandinavica 1998, 77(4):402-409.

28. Atuyambe L, Mirembe F, Johansson A, Kirumira EK, Faxelid E: Experiences of pregnant adolescents - voices from Wakiso district, Uganda. African health sciences 2005, 5(4):304-309.

29. Atuyambe L, Faxelid E, Mirembe F, Kirumira KE, Johansson A: Coping responses during pregnancy and early motherhood among adolescents in central Uganda. UP Manila Journal The Philippine Health Social Science Journal in press.

30. Mngadi PT, Zwane IT, Ahlberg BM, Ransjo-Arvidson AB: Family and community support to adolescent mothers in Swaziland. Journal of advanced nursing 2003, 43(2): I37-I44.

31. Kaye DK, Mirembe FM, Bantebya G, Johansson A, Ekstrom AM: Domestic violence during pregnancy and risk of low birth- 
weight and maternal complications: a prospective cohort study at Mulago Hospital, Uganda. Trop Med Int Health 2006, II(I0): I576-1584.

32. Kaye DK, Mirembe FM, Bantebya G, Johansson A, Ekstrom AM: Domestic violence as risk factor for unwanted pregnancy and induced abortion in Mulago Hospital, Kampala, Uganda. Trop Med Int Health 2006, I I(I):90-10I.

33. Naved RT, Azim S, Bhuiya A, Persson LA: Physical violence by husbands: magnitude, disclosure and help-seeking behavior of women in Bangladesh. Social science \& medicine (1982) 2006, 62(1 2):2917-2929.

34. Jonzon R, Vung ND, Ringsberg KC, Krantz G: Violence against women in intimate relationships: explanations and suggestions for interventions as perceived by healthcare workers, local leaders, and trusted community members in a northern district of Vietnam. Scandinavian journal of public health 2007, 35(6):640-647.

35. Thaddeus S, Maine D: Too far to walk: maternal mortality in context. Social science \& medicine (1982) 1994, 38(8): 1091-III0.

36. Tsu VD: Antenatal screening: its use in assessing obstetric risk factors in Zimbabwe. Journal of epidemiology and community health 1994, 48(3):297-305.

37. Kyomuhendo GB: Low use of rural maternity services in Uganda: impact of women's status, traditional beliefs and limited resources. Reproductive health matters 2003, I I(2I): 16-26.

38. Engebretsen IM, Wamani H, Karamagi C, Semiyaga N, Tumwine J, Tylleskar T: Low adherence to exclusive breastfeeding in Eastern Uganda: a community-based cross-sectional study comparing dietary recall since birth with 24-hour recall. $B M C$ pediatrics 2007, 7:10.

39. Wamani H, Astrom AN, Peterson S, Tylleskar T, Tumwine JK: Infant and young child feeding in western Uganda: knowledge, practices and socio-economic correlates. Journal of tropical pediatrics 2005, 5I(6):356-36I.

40. Luther NY: Mother's tetanus immunisation is associated not only with lower neonatal mortality but also with lower earlychildhood mortality. National Family Health Survey bulletin 1998:1-4.
Publish with Bio Med Central and every scientist can read your work free of charge

"BioMed Central will be the most significant development for disseminating the results of biomedical research in our lifetime. "

Sir Paul Nurse, Cancer Research UK

Your research papers will be:

- available free of charge to the entire biomedical community

- peer reviewed and published immediately upon acceptance

- cited in PubMed and archived on PubMed Central

- yours - you keep the copyright 